\title{
Rickettsia africae sp. nov., the Etiological Agent of African Tick Bite Fever
}

\author{
PATRICK J. KELLY, ${ }^{1}$ LORENZA BEATI, ${ }^{2}$ PETER R. MASON, ${ }^{3}$ \\ LINDA A. MATTHEWMAN, ${ }^{1}$ VÉRONIQUE ROUX, ${ }^{2}$ \\ AND DIDIER RAOULT ${ }^{2 *}$ \\ Department of Clinical Veterinary Studies, Faculty of Veterinary Science, ${ }^{1}$ \\ and Department of Medical Microbiology, Faculty of Medicine, ${ }^{3}$ \\ University of Zimbabwe, Harare, Zimbabwe, and Unité des \\ Rickettsies, Faculté de Médecine, Marseille, France ${ }^{2}$
}

\begin{abstract}
We propose the name Rickettsia africae sp. nov. (with type strain Z9-Hu) for a distinct species of spotted fever group (SFG) rickettsiae that is the etiological agent of African tick bite fever in humans. This rickettsia has a distinct natural cycle and can be phenotypically distinguished from the other SFG rickettsiae by microimmunofluorescence serotyping, by sodium dodecyl sulfate-polyacrylamide gel electrophoresis, and by Western blotting (immunoblotting). Genotypic differences between $R$. africae and the other SFG rickettsiae can be demonstrated by PCR restriction fragment length polymorphism analysis, pulsed-field gel electrophoresis, and sequencing of the $16 \mathrm{~S}$ rRNA gene.
\end{abstract}

Until recently, Rickettsia conorii was the only spotted fever group (SFG) rickettsia that had been reliably reported from Africa. Studies in our laboratories, however, have shown that there is another SFG rickettsia which is pathogenic in humans and ecologically, phenotypically, and genotypically distinct from $R$. conorii and the other SFG rickettsiae. In this paper we describe the characteristics of this organism and formally propose that it should be named Rickettsia africae.

Background. In the 1930s South African workers studied the relationship between tick bite fever, a disease described in southern Africa in $1911(25,27,36)$, and fièvre boutonneuse, which had been described in North Africa a year earlier (5). On the basis of clinical and epidemiological data, Adrianus Pijper considered the two diseases distinct and probably caused by different etiologic agents $(30-32,39)$. He noted that while fièvre boutonneuse was a more severe disease characterized by a skin rash and contact with dog ticks, in particular Rhipicephalus sanguineus (6), tick bite fever was a mild disease that was not associated with complications, mortality, or skin rash and occurred following travel into the veld and contact with ticks of cattle and wild animals, in particular Amblyomma spp. Also, experiments performed with guinea pigs failed to demonstrate cross-immunity between the agents of tick bite fever and fièvre boutonneuse (31). However, the findings of Pijper were not confirmed by subsequent workers $(9,13,14)$, and the epidemiological differences between tick bite fever and fièvre boutonneuse were explained as the result of age-related differences in behavior and susceptibility (8-11). Finally, the causative agent of fièvre boutonneuse, $R$. conorii Malish $7^{\mathrm{T}}$ $\left(=\right.$ ATCC VR-613 $\left.{ }^{\mathrm{T}}\right)(\mathrm{T}=$ type strain), (4), was isolated in South Africa, and subsequently, all cases of tick bite fever have been considered cases caused by infection with $R$. conorii (12).

Recent reports from southern Africa have provided strong epidemiological evidence that Amblyomma hebraeum, a tick known to readily feed on humans $(16,26)$, is the major vector

\footnotetext{
* Corresponding author. Mailing address: Unité des Rickettsies, Faculté de Médecine, 27, Boulevard Jean Moulin, Marseille, France. Phone: (33) 918343 75. Fax: (33) 918303 90. Electronic mail address: raoult@citi2.fr.
}

of tick bite fever in the region. This tick has been implicated in outbreaks of the disease in Rhodesian troops during the Zimbabwe War of Independence (26) and in United States airborne troops deployed in Botswana (17). In Zimbabwe, $A$. hebraeum is most prevalent in rural areas in the south of the country, where it mainly parasitizes domestic and wild ungulates (26). The southern part of Zimbabwe is also the area that has the highest incidence of clinical cases of tick bite fever (22) and the area shown by serosurveys to have the highest incidence of SFG rickettsial infections in people $(19,22)$ and domestic ruminants $(21,23)$. It has been shown that a high percentage ( $72 \%$ ) of $A$. hebraeum ticks are infected with rickettsia-like organisms (1), and feeding experiments performed with susceptible hosts have demonstrated that $A$. hebraeum can maintain SFG rickettsiae transtadially and transovarially and that each feeding stage can transmit the organisms $(20,23)$.

When six rickettsial isolates obtained from $A$. hebraeum ticks collected in widely separated areas of Zimbabwe and an isolate obtained from Amblyomma variegatum in Ethiopia (28) were compared by using microimmunofluorescence serotyping, sodium dodecyl sulfate-polyacrylamide gel electrophoresis (SDSPAGE), and Western blotting (immunoblotting), they were phenotypically indistinguishable from one another but distinct from the other SFG rickettsiae (18). As determined by microimmunofluorescence serotyping, the specificity differences (SPDs) between these seven isolates and the other SFG rickettsiae varied from 4 to 14 . These SPDs were calculated by the usual method, as follows: $\mathrm{SPD}=(\mathrm{Aa}+\mathrm{Bb})-(\mathrm{Ab}+\mathrm{Ba})$, where $\mathrm{Aa}$ or $\mathrm{Bb}$ is $-\log _{2}$ of the end point titer between serum $\mathrm{A}$ or $\mathrm{B}$ and homologous antigen $\mathrm{a}$ or $\mathrm{b}$ and $\mathrm{Ab}$ or $\mathrm{Ba}$ is $-\log _{2}$ of the end point titer of serum $\mathrm{A}$ or $\mathrm{B}$ against heterologous antigen $b$ or $a$. If the SPD is $<3$, two strains are assumed to be identical, and if the SPD is $\geq 3$, the strains are different (29). In addition, an isolate obtained from a patient in Zimbabwe who had a history of tick bites and signs of tick bite fever but no rash (24) was indistinguishable from isolates obtained from Amblyomma ticks as determined by the techniques mentioned above but was distinct from the other SFG rickettsiae. Therefore, the isolates obtained from Amblyomma ticks and the human isolate have been called the agent of African tick bite fever (AATBF) (18), and workers have obtained evidence that the 


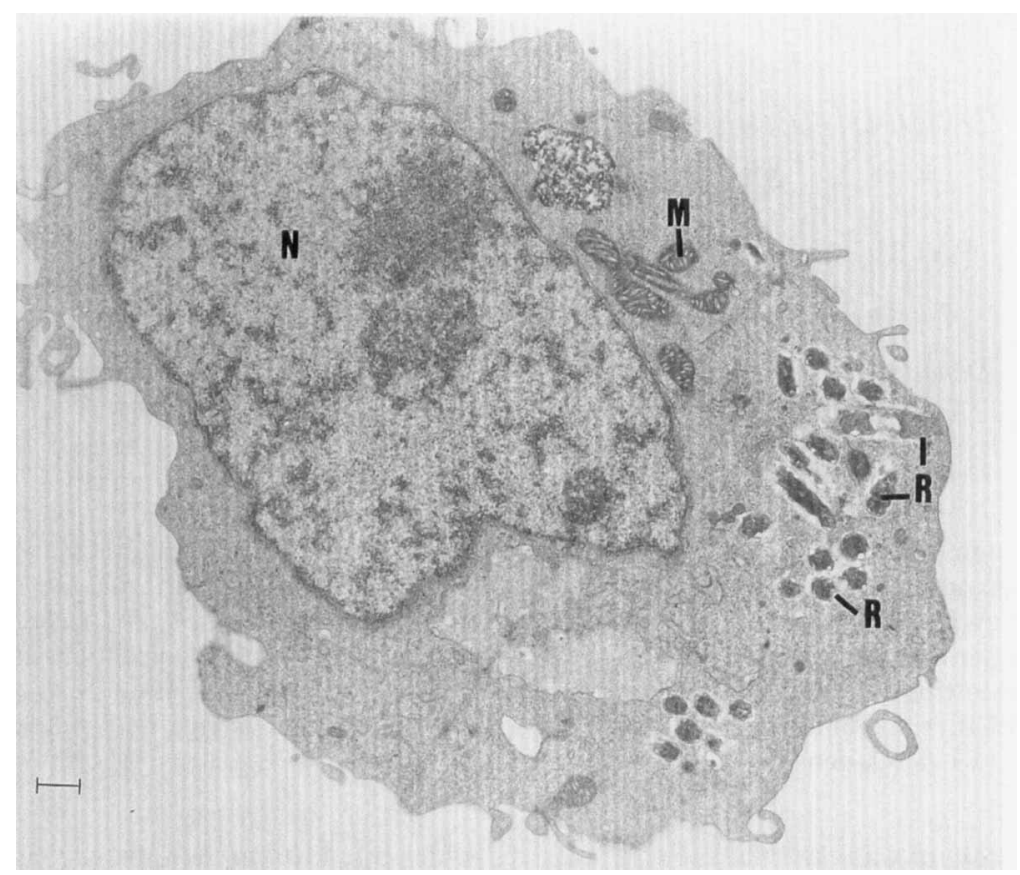

FIG. 1. Electron micrograph of $R$. africae infecting an L929 cell. R. rickettsia; M, mitochondrion; N, nucleus. Bar $=0.5 \mu \mathrm{m}$.

organisms are infective (38) and pathogenic in humans (unpublished data).

There are also genotypic differences between the AATBF and the other SFG rickettsiae. When we performed a PCR and restriction fragment length polymorphism analysis in which primers for the 120 - and $190-\mathrm{kDa}$ surface protein genes of Rickettsia rickettsii and digestion with RsaI and PstI (33) were used, AATBF could be differentiated from all other SFG rickettsiae except Rickettsia parkeri (7). The average genome size of the AATBF $(1,248 \mathrm{~kb})$ was estimated by digesting the DNA with EagI, SmaI, and BssHII and separating the resulting preparation by pulsed-field gel electrophoresis (PFGE), and the value obtained was consistent with the genome sizes of other SFG rickettsiae. However, the PFGE restriction profiles were different from those of the other SFG species (34). Moreover, the sizes of the digestion fragments on which the citrate synthase, the $120-\mathrm{kDa}$ surface protein, and the $190-\mathrm{kDa}$ surface protein genes were located were different from the sizes of the fragments obtained with the other SFG rickettsiae. A genetic relationship dendrogram established from the PFGE patterns obtained after SmaI, EagI, and BssHII digestion by using the Dice coefficient, the unweighted pair group with mathematical average method, and the Philip package program shows that the estimated levels of genetic divergence between the AATBF and other organisms are as follows: $35 \%$ with the closest relative, Rickettsia sibirica; $46 \%$ with a cluster of species containing $R$. parkeri, $R$. conorii, and the Israeli spotted fever rickettsia; and 47 to $74 \%$ with all other SFG rickettsiae (34). Sequencing studies have shown that the AATBF has a $16 \mathrm{~S}$ rRNA gene sequence that differs from the 16S rRNA gene sequences of all other SFG rickettsiae; the levels of homology range from $97.9 \%$ with Rickettsia akari, a relatively distantly related SFG species, to $99.6 \%$ with $R$. parkeri and $99.7 \%$ with $R$. sibirica, the closest relatives (35).

Justification for a new species. Currently, serological typing by microimmunofluorescence $(29)$ is the standard method for determining taxonomic relationships between $\mathrm{SFG}$ rickettsiae
$(2,3,40)$. Genomic species definitions of prokaryotic taxa are supposed to rely on DNA-DNA relatedness analysis data (43) rather than $16 \mathrm{~S}$ rRNA sequence data, particularly when the levels of $16 \mathrm{~S}$ ribosomal DNA similarity are $97 \%$ or higher (37). The levels of homology among SFG rickettsiae are more than $97.8 \%$ (35). However, criteria which have been established primarily by analyzing enterobacteria may not be suitable for the study of rickettsiae, which are strictly intracellular organisms characterized by small genomes (34) whose evolution is probably subjected to the different selective mechanisms inherent in their complex ecological and epidemiological cycles. Although the results of a DNA-DNA homology analysis indicated that the SFG rickettsiae belong to a single species (42), until the validity of such criteria for all eubacterial taxa is confirmed (41), a global approach based on phenotypic, immunological, genotypic, ecological, and clinical data seems to be more suitable for the definition of rickettsial species.

On the basis of the distinctive clinical, epidemiological, phenotypic, and genotypic features described above, and to differentiate between the two pathogenic SFG rickettsiae that have been found in Africa, we propose that the isolates that were obtained from Amblyomma spp. and a patient with a history of tick bites and clinical signs of tick bite fever should be considered a separate taxonomic species, for which we propose the name Rickettsia africae.

Description of Rickettsia africae sp. nov. Rickettsia africae (a' fri. cae. L. gen. n. africae, from Africa, the continent where the organism was isolated) is an obligately intracellular gram-negative bacterium. This organism can be grown in the yolk sacs of developing chicken embryos, which die 5 to 7 days following inoculation, and in L929, Vero, and human embryonic lung fibroblast cells. Plaque formation does not occur in infected Vero cells. Gimenez-stained (15) infected cells contain intracellular, rod-shaped organisms that are 0.3 to 0.5 by 0.9 to 1.6 $\mu \mathrm{m}$. Electron microscopy shows that the organisms occur free in the cytoplasm and have an outer slime layer and a trilaminar cell wall (Fig. 1). 
$R$. africae can be isolated from humans with a history of tick bites and clinical signs consistent with African tick bite fever and from $A$. hebraeum and $A$. variegatum. Stage-to-stage and transovarial transmission of the organism has been demonstrated in $A$. hebraeum, and all feeding stages of this tick can transmit the organism to rabbits. Adults can transmit the organism to goats. In these species and in Swiss Webster and $\mathrm{BALB} / \mathrm{c}$ mice, infections are subclinical, although antibodies to the organism are produced. At 4 to 6 days after intraperitoneal inoculation, guinea pigs may develop a mild fever $\left(>39.5^{\circ} \mathrm{C}\right.$ for 1 to 2 days), but they do not develop scrotal edema. In microimmunofluorescence tests the SPDs between $R$. africae and the other SFG rickettsiae are $>3$ (the SPD between $R$. africae and $R$. parkeri is 7, and the SPD between $R$. africae and $R$. sibirica is 5.5). As determined by SDS-PAGE, $R$. africae produces three distinct high-molecular-weight protein bands, at 117, 135 , and $138 \mathrm{kDa}$; the most prominent band is the $117-\mathrm{kDa}$ band. Sera from mice inoculated with $R$. africae have antibodies that react with these bands. $R$. africae can be differentiated from all other SFG rickettsiae, except $R$. parkeri by the results of PCR restriction fragment length polymorphism analysis. When amplified rickettsial DNA derived from PCRs with primers $\operatorname{Rr} 190.70 \mathrm{p}$ and $\mathrm{Rr} 190.602 \mathrm{n}$ is digested with restriction endonuclease $R s a \mathrm{I}, 343$ - and 220 -bp fragments are obtained (a $107-\mathrm{bp}$ fragment and a double 223-bp band are obtained with $R$. sibirica [7]); restriction endonuclease $P$ stI digests the DNA into of 267-, 124-, and 81-bp fragments. RsaI digestion of the products obtained from PCRs performed with primers BG 1-21 and BG 2-20 yields 163-, 133-, 102-, 88-, and 60-bp fragments.

As determined by PFGE, the estimated genome size of $R$. africae is $1,248 \mathrm{kDa}$. The PFGE profiles of the DNA of the organism obtained following digestion with EagI, SmaI, and $B s s$ HII are distinct from those of the other SFG rickettsiae. After digestion with Bss HII, the profile of $R$. africae is characterized by five fragments, the $R$. parkeri profile contains four bands (one in common with $R$. africae), and the $R$. sibirica profile contains four bands (two in common with $R$. africae); after restriction with $E a g I$ the profiles of these three organisms contain 16 bands, 7 of which are shared by $R$. africae and $R$. sibirica and 8 of which are shared by $R$. africae and $R$. parkeri; after digestion with $S m a$ I 8 of 25 fragments are shared by $R$. africae and $R$. parkeri and 18 fragments of 26 are shared by $R$. africae and $R$. sibirica (34). The bands on which the citrate synthase and $190-$ and $120-\mathrm{kDa}$ surface protein genes are located are distinct from the bands on which these genes are located in the other SFG rickettsiae following PFGE of the digestion products of endonucleases Bss HII and SmaI. $R$. africae has a $16 \mathrm{~S}$ rRNA gene sequence which differs from the $16 \mathrm{~S}$ rRNA gene sequences of the other SFG rickettsiae. Compared with $R$. rickettsii, $R$. africae has a TTT insertion at position $85 / 6$ and an A mutation at position 78 .

The illness. Previously, tick bite fever and fièvre boutonneuse have been considered different names for a single disease resulting from $R$. conorii infection. Therefore, the clinical features of these diseases have been considered to be the same (12). There is now strong evidence, however, that tick bite fever has a different etiological agent, and additional studies will be needed to determine more precisely the clinical features, prognosis, and therapy for the disease. The data available and our unpublished findings suggest that tick bite fever results from bites of infected Amblyomma spp. encountered during travel into rural areas. An eschar develops at the bite site, and regional lymphadenopathy, mild fever, and severe headache follow. The absence of a skin rash appears to be a characteristic feature of the disease.
Type strain. The type strain of $R$. africae is strain $\mathrm{Z} 9-\mathrm{Hu}$, an isolate obtained from a person with tick bite fever; this strain has been deposited in the Collection of the World Health Organization Collaborative Center for Rickettsial Reference, Marseille, France.

Nucleotide sequence accession number. The $16 \mathrm{~S}$ rRNA gene sequence of $R$. africae $\mathrm{Z} 9-\mathrm{Hu}^{\mathrm{T}}$ has been deposited in the GenBank data library under accession number L36098.

We thank Guy Vestris for expert technical assistance.

Funding was provided by the Research Board of the University of Zimbabwe and the European Community-funded link between the Veterinary Faculties of the Universities of Zimbabwe and Utrecht.

\section{REFERENCES}

1. Beati, L., P. J. Kelly, L. A. Matthewman, P. R. Mason, and D. Raoult. 1995. The prevalence of rickettsia-like organisms and spotted fever group rickettsiae in ticks (Acari: Ixodidae) from Zimbabwe. J. Med. Entomol. 32:787-792.

2. Beati, L., O. Péter, W. Burgdorfer, A. Aeschlimann, and D. Raoult. 1993. Confirmation that Rickettsia helvetica sp. nov. is a distinct species of the spotted fever group of rickettsiae. Int. J. Syst. Bacteriol, 43:521-526.

3. Beati, L., and D. Raoult. 1993. Rickettsia massiliae sp. nov., a new spotted fever group rickettsia. Int. J. Syst. Bacteriol. 43:839-840.

4. Brumpt, E. 1932. Longévité de virus de la fièvre boutonneuse (Rickettsia conorii, n.sp.) chez la tique. Rhipicephalus sanguineus. C. R. Seances Soc. Biol. 110:1199-1209.

5. Conor, A., and A. Bruch. 1910. Une fièvre éruptive observée en Tunisie. Bull. Soc. Pathol. Exot. 8:139-142.

6. Durand, P., and L. Conseil. 1930. Transmission de la fièvre exanthémique par la tique du chien. C. R. Acad. Sci. 190:1244-1254.

7. Eremeeva, M., X. J. Yu, and D. Raoult. 1994. Differentiation among spotted fever group rickettsia species by analysis of restriction fragment length polymorphism of PCR-amplified DNA. J. Clin. Microbiol. 32:803-810.

8. Gear, J. H. S. 1938. South African typhus. S. Afr. J. Med. Sci. 3:134-160.

9. Gear, J. H. S. 1939. Complications in tick-bite fever. A survey of fifty cases. S. Afr. Med. J. 13:35-38.

10. Gear, J. H. S. 1941. The typhus group of fevers. Leech 17:7-16.

11. Gear, J. H. S. 1954. The rickettsial diseases of southern Africa. S. Afr. J. Clin. Sci. 5:158-174

12. Gear, J. H. S. 1988. Other spotted fever group rickettsioses: clinical signs, symptoms, and pathology, p. 101-115. In D. Walker (ed.), Biology of rickettsial diseases, vol. 1. CRC Press, Inc., Boca Raton, Fla.

13. Gear, J. H. S., and C. Bevan. 1936. An outbreak of tick-bite fever. S. Afr. Med. J. 10:485--488.

14. Gear, J. H. S., and B. De Meillon. 1941. The hereditary transmission of the rickettsia of tick-bite fever through the common dog tick Haemaphysalis leachi. S. Afr. Med. J. 15:389-392.

15. Gimenez, D. F. 1964. Staining rickettsiae in yolk sac cultures. Stain Technol. 39:135-140.

16. Hoogstraal, H. 1956. African Ixodoidea. I. Ticks of the Sudan. Research Report NIM 0050502907. U. S. Government Printing Office, Washington, D. C.

17. Kelly, D. J., G. A. Dasch, B. L. Smoak, B. McClain, J. F. Brundage, L. Broadhurst, C. T. Chan, and R. N. Miller. 1992. Etiology of a rickettsial disease outbreak in US troops returning from deployment in Botswana, p. 9. In Abstracts of the 10th Sesqui-Annual Meeting of the American Society for Rickettsiology and Rickettsial Diseases. Rocky Mountain Laboratories, Hamilton, Mont.

18. Kelly, P. J., L. Beati, L. A. Matthewman, P. R. Mason, G. A. Dasch, and D. Raoult. 1994. A new pathogenic spotted fever group ricketisia from Africa. J. Trop. Med. Hyg. 97:129-137.

19. Kelly, P. J., and P. R. Mason. 1991. Tick-bite fever in Zimbabwe: a survey for antibodies to Rickettsia conorii in man and dogs and rickettsia-like organisms in dog ticks. S. Afr. Med. J. 80:233-236.

20. Kelly, P. J., and P. R. Mason. 1991. Transmission of a spotted fever group rickettsia by Amblyomma hebraeum (Acari; Ixodidae). J. Med. Entomol. 28:598-600.

21. Kelly, P. J., P. R. Mason, T. Manning, and S. Slater. 1991. Role of cattle in the epidemiology of tick-bite fever in Zimbabwe. J. Clin. Microbiol. 29:256259.

22. Kelly, P. J., P. R. Mason, L. A. Matthewman, and D. Raoult. 1991. Seroepidemiology of spotted fever group rickettsial infections in humans in Zimbabwe. J. Trop. Med. Hyg. 94:304-309.

23. Kelly, P. J., P. R. Mason, C. Rohde, F. Dziva, and L. A. Matthewman. 1991. Transient infections of goats with a novel spotted fever group rickettsia from Zimbabwe. Res. Vet. Sci. 51:268-271.

24. Kelly, P. J., L. A. Matthewman, L. Beati, D. Raoult, P. R. Mason, M. Deary, and J. Makombe. 1992. African tick-bite fever: a new spotted fever group rickettsiosis under an old name. Lancet 340:982-983. 
25. McNaught, J. G. 1911. A tick-bite fever in the Union of South Africa. J. R Army Med. Corps 16:505.

26. Norval, R. A. I. 1983 . The ticks of Zimbabwe. VII. The genus Amblyomma. Zimbabwe Vet. J. 14:3-18.

27. Nutall, G. H. F. 1911. On symptoms following tick-bite in man. Parasitology 4:89-93.

28. Philip, C. B., H. Hoogstraal, R. Reiss-Gutfreund, and C. M. Clifford. 1966 Evidence of rickettsial disease agents in ticks from Ethiopian cattle. Bull. W. H. O. 35:127-131.

29. Philip, R. N., E. A. Casper, W. Burgdorfer, R. K. Gerloff, L. B. Hughes, and E. J. Bell. 1978. Serologic typing of rickettsiae of the spotted fever group by microimmunofluorescence. J. Immunol. 121:1961-1968.

30. Pijper, A. 1934. Tick-bite fever. A clinical lecture. S. Afr. Med. J. 8:551-556.

31. Pijper, A. 1936. Etude expérimentale comparée de la fièvre boutonneuse et de la tick-bite fever. Arch. Inst. Pasteur Tunis 25:388-401.

32. Pijper, A., and C. G. Crocker. 1938. Rickettsioses of South Africa. S. Afr. Med. J. 12:613-30.

33. Regnery, R. L., C. L. Spruill, and B. D. Plikaytis. 1991. Genotypic identification of rickettsiae and estimation of intraspecies sequence divergence for portions of two rickettsial genes. J. Bacteriol. 173:1576-1589.

34. Roux, V., and D. Raoult. 1993. Genotypic identification and phylogenetic analysis of the spotted fever group rickettsiae using pulsed-field gel electrophoresis. J. Bacteriol. 175:4895-4904.

35. Roux, V., and D. Raoult. 1995. Phylogenetic analysis of the genus Rickettsia by $16 \mathrm{~S}$ rDNA sequencing. Res. Microbiol. 146:385-396.
36. Sant'Anna, J. F. 1911. On a disease in man following tick-bites and occuring in Lourenço Marques. Parasitology 4:87-88.

37. Stackebrandt, E., and B. M. Goebel. 1994. Taxonomic note: a place for DNA-DNA reassociation and 16S rRNA sequence analysis in the present species definition in bacteriology. Int. J. Syst. Bacteriol. 44:846-849.

38. Tissot Dupont, H., P. Brouqui, B. Faugere, and D. Raoult. 1995. The prevalence of antibodies to Coxiella burnetii, Rickettsia conorii, and Rickettsia typhi in seven African countries. Clin. Infect. Dis. 21:1123-1126.

39. Troup, J. M., and A. Pijper. 1938. Tick-bite fever in southern Africa. Lancet ii: $1183-1186$.

40. Uchida, T., T. Uchiyama, K. Kumano, and D. H. Walker. 1992. Rickettsia japonica sp. nov., the etiological agent of spotted fever group rickettsiosis in Japan. Int. J. Syst. Bacteriol. 42:303-305.

41. Vancanneyt, M., P. Vandamme, and K. Kersters. 1995. Differentiation of Bordetella pertussis, B. parapertussis, and B. bronchiseptiica by whole-cell protein electrophoresis and fatty acid analysis. Int. J. Syst. Bacteriol. 45:843847.

42. Walker, D. H. 1989. Rocky Mountain spotted fever: a disease in need of microbiological concern. Clin. Microbiol. Rev. 2:227-240.

43. Wayne, L. G., D. J. Brenner, R. R. Colwell, P. A. D. Grimont, O. Kandler, M. I. Krichevsky, L. H. Moore, W. E. C. Moore, R. G. E. Murray, E. Stackbrandt, M. P. Starr, and H. G. Trüper. 1987. Report of the Ad Hoc Committee on Reconciliation of Approaches to Bacterial Systematics. Int. J. Syst. Bacteriol. 37:463-464. 